\title{
Multiple sclerosis starting before the age of 18 years: the Brazilian experience
}

Esclerose múltipla com início antes dos 18 anos de idade: a experiência brasileira

Yara Dadalti Fragoso', Maria Lucia Brito Ferreira², Nivea de Macedo Oliveira Morales ${ }^{3}$, Walter Oleschko Arruda ${ }^{4}$, Joseph Bruno Bidin Brooks', Denise Sisterolli Diniz Carneiro ${ }^{5}$, Margarete de Jesus Carvalho ${ }^{6}$, Elizabeth Regina Comini-Frota7, Eber Castro Correa ${ }^{8}$, Carlos Augusto de Albuquerque Damasceno ${ }^{9}$, Renan Barros Domingues ${ }^{10}$, Alessandro Finkelsztejn ${ }^{11}$, Paulo Diniz da Gama ${ }^{12}$, Sidney Gomes ${ }^{13}$, Marcus Vinicius Magno Gonçalves ${ }^{14}$, Anderson Kuntz Grzesiuk ${ }^{15}$, Jussara Mathias Netto Khouri'16, Damacio Ramon Kaimen-Maciel'7, Maria Fernanda Mendes ${ }^{18}$, Rogerio de Rizo Morales ${ }^{3}$, Sonia Beatriz Felix Ribeiro ${ }^{19}$, Taysa Alexandrino Gonsalves Jube Ribeiro ${ }^{5}$, Livia Brito Bezerra de Albuquerque?2, Andrea Anacleto ${ }^{1,20}$, Juliana Finkelsztejn"11, Rodrigo Assad Diniz da Gama12, Josiane Lopes ${ }^{17}$, Celso Luis Silva Oliveira ${ }^{1}$, Francisco Tomaz Meneses Oliveira ${ }^{13}$, Leopoldo Antônio Pires ${ }^{9}$, Patricia Correia de Oliveira Saldanha ${ }^{10}$, Adélia Henriques Souza ${ }^{2}$, Alex Eduardo da Silva ${ }^{19}$

\begin{abstract}
Multiple sclerosis (MS) starting in childhood and adolescence poses a challenge for diagnosis and management of the disease. The aim of the present study was to assess the characteristics of early onset MS in Brazilian patients. Methods: Retrospective data collection from specialized MS units. Results: From 20 MS units in 11 Brazilian states, 117 cases of MS starting before the age of 18 years were collected. These patients had an average of 10 years of disease duration, still typically with low disability and one relapse every 2.5 years. The mean age for disease onset was 13.7 years. Conclusion: The present study introduces a large series of Brazilian cases of pediatric MS. Although some patients presented a very severe form of MS, on the whole the group of patients with MS starting in childhood or adolescence presented a relatively mild form of this disease in Brazil.
\end{abstract}

Keywords: multiple sclerosis, children, adolescents, pediatrics.

\footnotetext{
${ }^{1}$ Universidade Metropolitana de Santos, Santos SP, Brazil;

${ }^{2}$ Hospital da Restauração, Recife PE, Brazil;

${ }^{3}$ Universidade Federal de Uberlândia, Uberlândia MG, Brazil;

«Universidade Federal do Paraná, Curitiba PR, Brazil;

${ }^{5}$ Universidade Federal de Goiás, Goiânia GO, Brazil;

${ }^{6}$ Fundação ABC, Santo André SP, Brazil;

${ }^{7}$ Universidade Federal de Minas Gerais, Belo Horizonte MG, Brazil;

${ }^{8}$ CLINEN - Neurologia e Endocrinologia, Brasília DF, Brazil;

${ }^{9}$ Universidade Federal de Juiz de Fora, Juiz de Fora MG, Brazil;

${ }^{10}$ Faculdade de Ciências da Saúde, Santa Casa de Vitória, Vitória ES, Brazil;

${ }^{11}$ Hospital de Clínicas de Porto Alegre, Porto Alegre RS, Brazil;

${ }^{12}$ Pontifícia Universidade Católica de São Paulo, Campus Sorocaba, Sorocaba SP, Brazil;

${ }^{13}$ Hospital Beneficência Portuguesa and Hospital Paulistano, São Paulo SP, Brazil;

${ }^{14}$ Universidade da Região de Joinville, Joinville SC, Brazil;

${ }^{15}$ Centro de Reabilitação Center Dom Aquino Correa, Cuiabá MT, Brazil;

${ }^{16}$ Universidade Federal do Rio de Janeiro, Macaé RJ, Brazil;

${ }^{17}$ Universidade Estadual de Londrina, Londrina PR, Brazil;

${ }^{18}$ Santa Casa de São Paulo, São Paulo SP, Brazil;

${ }^{19}$ Universidade Federal do Triângulo Mineiro, Uberaba MG, Brazil;

${ }^{20}$ Hospital Ana Costa de Santos, Santos SP, Brazil.
}

Correspondence: Yara Dadalti Fragoso; Department of Neurology / Medical School, UNIMES; Rua da Constituição 374; 11015 -470 Santos SP - Brasil; E-mail:yara@bsnet.com.br

Conflict of interest: There is no conflict of interest to declare.

Received 29 April 2013; Received in final form 17 May 2013; Accepted 24 May 2013. 
Esclerose múltipla (EM) com início na infância e adolescência constitui um desafio para o diagnóstico e manejo da doença. A proposta do presente estudo foi avaliar as características da EM de início precoce em pacientes brasileiros. Métodos: Coleta de dados retrospectiva de arquivos de unidades especializadas em atendimento da EM. Resultados: A partir de 20 unidades de EM de nove estados brasileiros, foram coletados 117 casos de EM com início antes dos 18 anos de idade. Estes pacientes tinham uma média de 10 anos de duração da doença, de maneira geral apresentavam pouca incapacidade , com um surto a cada dois anos e meio. A média de idade no início da doença era 13,7 anos. Conclusão: 0 presente estudo apresenta uma grande série de casos brasileiros de EM pediátrica. Embora alguns pacientes tenham apresentado forma grave de EM, de maneira geral o grupo de pacientes cuja EM iniciou-se na infância ou adolescência apresentou uma forma relativamente leve da doença no Brasil.

Palavras-chave: esclerose múltipla, crianças, adolescentes, pediatria.

Multiple sclerosis (MS) is a chronic inflammatory and degenerative neurological disease that typically affects young adults. MS usually appears between the ages of 20 and 40 years, and an early start of MS ( $<18$ years old) is relatively uncommon ${ }^{1}$. Diagnosis and management of these patients require special attention ${ }^{2-5}$. Few case series on the epidemiology and characteristics of MS starting in childhood and adolescence have been published in the world. Except for four papers ${ }^{6-9}$, other publications have presented fewer than 100 cases each in their series ${ }^{10-23}$.

When MS in Brazilian children and adolescents is considered, it is possible that some aspects are different from MS of European, Asian, North African, and North American counterparts. In Brazil, children have a more mixed genetic background, more frequent infestations by helminths, and high sun exposure since early life. These are genetic and environmental factors that may positively affect MS development and evolution. The present study aimed to better understand the epidemiological profile of early-onset MS in Brazilian patients. A specific database was set up to collect data from patients with MS whose disease started before the patient reached his/her 18th birthday.

\section{METHOD}

The present study was approved by the Ethics Committee of Universidade Metropolitana de Santos, SP, under number CAAE 13499913.7.0000.5509. Further approvals were obtained from institutions participating in the study that required additional submission to their Ethics Committees. No public, governmental, or private financial support was received for creating this database and for preparing this paper.

Brazilian neurologists and neuropediatricians caring for patients with MS were invited to participate in the study. The study was based on the medical records of patients under the care of the physicians sending the information. A specific file with demographic and clinical information on each patient was sent to the authors, and data collection took place between October and December 2012. Only cases with complete information were included in the analysis. Cases resembling acute disseminated encephalomyelitis, neuromyelitis optica (NMO), or spectrum disorders of NMO (NMO-SD) were excluded from this assessment.

All cases fulfilled McDonald's diagnostic criteria, revised for the pediatric population ${ }^{3}$, and the recommendations of the expert consensus for diagnosing pediatric $\mathrm{MS}^{24}$. No cases of demyelinating diseases other than MS were included in the present study. Disability was assessed using the Expanded Disability Scale Score (EDSS) ${ }^{25}$ and the clinical presentations of MS were defined as relapsing-remitting, secondary progressive, and primary progressive ${ }^{26}$.

Statistical analysis was carried out using Student's $t$-test for continuous data, and Fisher's exact test and the chisquare test for categorical data. Whenever correlations were required, Pearson's correlation test was used. However, due to the characteristics of the study, many results are presented only in a descriptive manner.

\section{RESULTS}

Data were collected from 20 MS units in different cities in 11 Brazilian states. Together, these MS units had 2290 MS patients registered and 125 of them (5.5\%) presented MS starting before the age of 18 years. A summary of the demographic and clinical data on these patients is presented in Table 1.

The average age at the time of disease onset was $13.7 \pm 3.4$ years (range 4-17 years). In 19 patients (15\%) the disease started when they were children, i.e. before reaching 11 years of age (onset of MS ranging from 4 to 10 years of age; mean $7.7 \pm 2.0$ years). In the remaining 108 patients (85\%) the disease started after 11 years of age. In this group of older children the age of onset of the disease was $14.8 \pm 1.6$ years (range 11-17 years). For the purpose of most analyses in this study, these two age groups were considered to be a single group of patients with MS starting in childhood or adolescence.

The total group consisted of 38 boys and 87 girls (1:2.3), and their ethnic background was either Caucasian (57 cases, $45.6 \%$ ) or African descent (68 cases, 54.4\%). There were no cases of children or adolescents descended from Asians or 
indigenous ancestors. All the children were born between the latitudes of $7^{\circ} 9^{\prime} 28^{\prime \prime}$ south and $30^{\circ} 2^{\prime} 77^{\prime \prime}$ south. At present, the average age of these patients is $23.3 \pm 9.3$ years.

Despite an average age of 13.7 years for disease onset, confirmation of MS was only possible at an average age of $15.7 \pm 6.2$ years. The initial presenting sign or symptom was most frequently multifocal (30 cases), involving the brainstem in 11 cases and/or the cerebellum in eight cases. When these occur separately, the most frequent presentations were sensory symptoms (22 cases), brainstem involvement (18 cases), cerebellar signs (17 cases), optic neuritis (16 cases), motor signs (16 cases), and spinal cord disease (three cases). Three cases were atypical, with one case of mental confusion, one of seizure, and one of hemianopsia. Motor presentation was either pyramidal (10 cases) or extrapyramidal (6 cases).

At the time of writing, 117 cases were in the form of relapsing-remitting MS, while six cases were secondary progressive MS. Two children died during the course of the disease.

The patients had suffered from MS for an average of $10.5 \pm 8.4$ years and their current EDSS was, on average, $1.96 \pm 2.24$. There was a moderate correlation between disease duration and degree of disability assessed by EDSS ( $\mathrm{r}=0.519)$. It is of interest to note that EDSS $\geq 6.0$ was significantly associated with MS starting before age 11 years (Fisher's exact test $\mathrm{p}=0.011$ ). The average disease duration for patients with EDSS $\geq 6.0$ in the present group was $23.3 \pm 17.6$ years. The disease duration among the more disabled patients was significantly longer $(p=0.0009)$ than that of patients currently with EDSS $\leq 6.0$.

Ninety-eight patients had normal intelligence and were currently doing well in school, whereas 11 patients were reported to have excelled at school. Fourteen patients presented moderate difficulties at school, but had not failed. Four of

Table 1. Demographical and clinical characteristics of 125 patients with multiple sclerosis starting before the 18th birthday.

\begin{tabular}{lc}
\hline & $n=125$ \\
\hline Age of onset & $13.7 \pm 3.4$ (range 4-17) years \\
Gender & 15\% started MS before completing 11 years \\
85\% started MS after 11th birthday \\
Ethnicity & Caucasians, $n=57$ \\
Initial & African descent, $n=68$ \\
presentation & Multifocal, $n=30$ \\
& Sensitive symptoms, $n=22$ \\
& Brainstem signs, $n=18$ \\
& Cerebellar signs, $n=17$ \\
Optic neuritis, $n=16$ \\
Spinal cord signs, $n=3$ \\
Atypical, $n=3$ \\
Disease duration & $10.5 \pm 8.4$ years \\
Present EDSS & $1.96 \pm 2.24$ (range $0-10$ ) \\
Relapses & $4.2 \pm 2.4$ during the disease \\
& Annual relapse rate $=0.34 \pm 0.27$ \\
\hline
\end{tabular}

EDSS: expanded disability scale score. these required additional private tuition. Two patients had been attending special schools for the disabled and were having great difficulties with their education.

At the time of writing, with an average of about 10 years of MS duration, the patients had experiences an average of 4.2 \pm 2.4 disease relapses (median=4). Twelve patients presented 10 or more relapses during their disease. There was no correlation between disease duration and number of relapses $(r=0.229)$ or disability and number of relapses $(r=0.240)$.

Disease progression among patients who started MS in childhood ( $\leq 10$ years ) was compared with progression among those with MS starting later in childhood ( $\geq 11$ years). Patients starting MS before age 11 years presented $E D S S=1.5 \pm 2.8$ after 5.5 years of disease duration. Those starting the disease after 11 years of age presented EDSS $=1.0 \pm 2.0$ after 14 years of disease duration $(\mathrm{p}=0.51)$.

Regarding treatment, 113 patients were currently receiving immunomodulatory and/or immunosuppressive medications for MS. There were 10 patients who for a variety of reasons were not treated, but mainly because they (and their families) did not want MS drug treatment. The remaining two patients died during the course of the disease.

The therapeutic options for these patients were extremely variable and are summarized in Table 2. Forty-one patients (32.8\% of the total sample) were on their second or third different therapeutic scheme because of failure or intolerance.

All patients had received at least one pulse of corticosteroids during the course of the disease. Seven patients had been diagnosed with depression and were receiving antidepressants. Among other drugs used by the patients were sildenafil and baclofen, both for rare and specific cases. Use of physiotherapy and hydrotherapy was reported by 15 patients ( $12 \%$ of the cases).

There were no cases of other immunological diseases diagnosed among the patients of this group. Three patients had other cases of MS in the family (the mother of one patient and the cousin of two different patients).

\section{DISCUSSION}

While the present database does not represent the whole of Brazil, it covers a large geographical region incorporating several states and many professionals working in MS units in this country. There is no national database for registration of MS and other demyelinating diseases, and two previous Brazilian case series have reported on specific areas of the country ${ }^{16,22}$. The present study is the first large national series of cases of MS starting in childhood or adolescence.

The percentage of early-onset MS cases in Brazil, namely $5.5 \%$ of all MS cases, is in accordance with the worldwide literature $^{9}$, although some authors reviewing the subject consider it to be below $5 \%{ }^{4}$. The present study did not analyze the 
Table 2. List of medications currently in use for multiple sclerosis in 113 patients. Eleven patients were not using any drugs and two patients had died at the time of this assessment.

\begin{tabular}{lc}
\hline Medication in use & Number of cases \\
\hline Glatiramer acetate & 39 \\
Interferon beta 1a 22 or $44 \mu \mathrm{g}$ & 21 \\
Interferon beta 1a $30 \mu \mathrm{g}$ & 17 \\
Interferon beta $1 \mathrm{~b} 250 \mu \mathrm{g}$ & 12 \\
Natalizumab & 9 \\
Azathioprine & 3 \\
Azathioprine + glatiramer acetate & 3 \\
Azathioprine + interferon beta & 3 \\
1a 22 or 44 $\mu \mathrm{g}$ & \\
Fingolimod & 2 \\
Immunoglobulin (monthly) & 2 \\
Cyclophosphamide + glatiramer acetate & 1 \\
Corticosteroids (monthly) & 1 \\
\hline
\end{tabular}

prevalence of childhood and adolescence MS in the different regions of the country. The numbers are too small to reach conclusions and, therefore, only the prevalence of earlier onset MS in relation to later onset MS can be discussed. The analyses on these data did not taken into consideration environmental or genetic factors that might influence the findings.

The overall results from the present study showed that those patients who started MS before the age of 18 years were not severely disabled after the average disease duration of 10 years. Other authors have remarked that MS in childhood typically predicts a favorable short- to medium-term prognosis ${ }^{27}$, which can account for the relatively low degree of disability among our patients. In fact, after suffering from MS for 30 years, $50 \%$ of these children are likely to enter the secondary progressive phase of the disease ${ }^{27}$. The patients in our cohort also had a good history of schooling, no associated diseases, and about one relapse every 2.5 years. Although isolated cases in our series progressed in a severe manner, the vast majority of the Brazilian patients starting MS before the age of 18 years were not particularly complicated cases. Theories that may account for the better disease course among Brazilian children and adolescents with MS include those relating to helminthic infections in childhood ${ }^{28}$, sunlight exposure ${ }^{29}$, and the typical national mixed race genetic background ${ }^{30}$.

Finally, the rich variety of signs and symptoms of MS presenting during childhood and adolescence needs to be thoroughly known and understood by pediatricians ${ }^{31}$. Delays in diagnosing and treating these patients may negatively affect the disease course, and close monitoring of these patients by neurologists and neuropediatricians is very important. The average typical delay of 2 years to obtain the diagnosis of MS in our population of youngsters needs to be decreased in the near future.

\section{References}

1. Chabas D, Strober J, Waubant E. Pediatric multiple sclerosis. Curr Neurol Neurosci Rep 2008;8:434-441.

2. Ghezzi A. Childhood-juvenile multiple sclerosis: clinical characteristics and treatment. Expert Rev Neurother 2005;5:403-411.

3. Polman CH, Reingold SC, Edan G, et al. Diagnostic criteria for multiple sclerosis: 2005 revisions to the "McDonald Criteria". Ann Neurol 2005;58:840-846.

4. Renoux C, Vukusic S, Confavreux C. The natural history of multiple sclerosis with childhood onset. Clin Neurol Neurosurg 2008;110:897-904.

5. Ghezzi A, Banwell B, Boyko A, et al. The management of multiple sclerosis in children: a European view. Mult Scler 2010;16:1258-1267.

6. MikaeloffY, Caridade G, Assi S, Suissa S, Tardieu M. Prognostic factors for early severity in a childhood multiple sclerosis cohort. Pediatrics 2006; 118:1133-1139.

7. Renoux C, Vukusic S, Mikaeloff Y, et al. Natural history of multiple sclerosis with childhood onset. N Engl J Med 2007;356:2603-2613.

8. Stark W, Huppke P, Gartner J. Paediatric multiple sclerosis: the experience of the German Centre for Multiple Sclerosis in Childhood and Adolescence.J Neurol 2008; 255(Suppl 6):S119-S122.

9. Harding KE, Liang K, Cossburn MD, et al. Long-term outcome of paediatric-onset multiple sclerosis: a population-based study. J Neurol Neurosurg Psychiatry 2013;84:141-147.

10. Brass SD, Caramanos Z, Santos C, Dilenge ME, Lapierre Y, Rosenblatt
B. Multiple sclerosis vs acute disseminated encephalomyelitis in childhood. Pediatr Neurol 2003;29:227-231.

11. Ozakbas S, Idiman E, Baklan B, Yulug B. Childhood and juvenile onset multiple sclerosis: clinical and paraclinical features. Brain Dev 2003;25:233-236.

12. Shiraishi K, Higuchi Y, Ozawa K, Hao Q, Saida T. Clinical course and prognosis of 27 patients with childhood onset multiple sclerosis in Japan. Brain Dev 2005;27:224-227.

13. Weng WC, Yang CC, Yu TW, Shen YZ, Lee WT. Multiple sclerosis with childhood onset: report of 21 cases in Taiwan. Pediatr Neurol 2006;35:327-334.

14. Xiong $\mathrm{H}$, Zhang $\mathrm{YH}$, Zhou R, et al. Clinical features and management of multiple sclerosis in children. Zhonghua $\mathrm{Er} \mathrm{Ke} \mathrm{Za} \mathrm{Zhi}$ 2007; 45:568-573.

15. Etemadifar M, Nasr-Esfahani AH, Khodabandehlou R, Maghzi AH. Childhood-onset multiple sclerosis: report of 82 patients from Isfahan, Iran. Arch Iran Med 2007;10:152-156.

16. Ferreira ML, Machado MI, Dantas MJ, Moreira AJ, Souza AM. Pediatric multiple sclerosis: analysis of clinical and epidemiological aspects according to National MS Society Consensus 2007. Arq Neuropsiquiatr 2008;66:665-670.

17. Neuteboom RF, Ketelslegers IA, Boon M, Catsman-Berrevoets $\mathrm{CE}$, Hintzen RQ. Barkhof magnetic resonance imaging criteria predict early relapse in pediatric multiple sclerosis. Pediatr Neurol 2010;42:53-55. 
18. Torisu H, Kira R, Ishizaki Y, et al. Clinical study of childhood acute disseminated encephalomyelitis, multiple sclerosis, and acute transverse myelitis in Fukuoka Prefecture, Japan. Brain Dev 2010;32:454-462.

19. Cocco E, Sardu C, Massa R, et al. Epidemiology of multiple sclerosis in south-western Sardinia. Mult Scler 2011;17:1282-1289.

20. Achiron A, Garty BZ, Menascu S, Magalashvili D, Dolev M, Ben-Zeev B, Pinhas-Hamiel O. Multiple sclerosis in Israeli children: incidence, an clinical, cerebrospinal fluid and magnetic resonance imaging findings. Isr Med Assoc J 2012;14:234-239.

21. Peña JA, Ravelo ME, Rubio E, Pirela D, Soto A, Nava CM. Pediatric multiple sclerosis in Venezuela. Arq Neuropsiquiatr 2012;70:267-270.

22. Fragoso YD, Brooks JBB, Leal TMS. Descriptive profile of multiple sclerosis starting until the age of 16 in the reference center of the state of São Paulo. Rev Paul Pediatr 2012;30:617-620.

23. Al-Hamadani HA, Abdalla AS, Al-Saffar AJ. The course of earlyonset multiple sclerosis in Iraqi children. World $J$ Pediatr 2012;8:47-51.

24. Krupp LB, Banwell B, Tenenbaum S. Consensus definitions proposed for pediatric multiple sclerosis and related disorders. Neurology 2007;68(Suppl 2):S7-S12.
25. Kurtzke JF. Rating neurologic impairment in multiple sclerosis: an expanded disability status scale (EDSS). Neurology 1983;33:1444-1452.

26. Lublin FD, Reingold SC. Defining the clinical course of multiple sclerosis: results of an international survey. National Multiple Sclerosis Society (USA) Advisory Committee on Clinical Trials of New Agents in Multiple Sclerosis. Neurology 1996;46:907-911.

27. Banwell B, Ghezzi A, Bar-Or A, Mikaeloff Y, Tardieu M. Multiple sclerosis in children: clinical diagnosis, therapeutic strategies, and future directions. Lancet Neurol 2007;6:887-902.

28. Elliott DE, Weinstock JV. Helminth-host immunological interactions: prevention and control of immune-mediated diseases. Ann N Y Acad Sci 2012;1247:83-96.

29. D'hooghe MB, Haentjens P, Nagels G, Garmyn M, De Keyser J. Sunlight exposure and sun sensitivity associated with disability progression in multiple sclerosis. Mult Scler 2012;18:451-459.

30. Kallaur AP, Kaimen-Maciel DR, Morimoto HK, Watanabe MA, Georgeto SM, Reiche EM. Genetic polymorphisms associated with the development and clinical course of multiple sclerosis. Int J Mol Med 2011;28:467-479.

31. Bigi S, Banwell B. Pediatric multiple sclerosis. J Child Neuro 2012;27:1378-1383. 